\title{
Experiencing Elegy: Materiality and Visuality in the Ambracian Polyandrion
}

\author{
Seth Estrin*
}

\section{Introduction}

To talk about a poem's genre is not simply to place it in an analytic category or performance context, but to bring to the surface structures that underlie it. The structural nature of genre allows it to intersect with features of a poem's performance that would have been immediately accessible to audiences in antiquity, but that today can only be discursively reconstructed. Our ability to understand how a poem's genre relates to the visual and auditory spectacle of its performance is, in most cases, limited by the nature of the evidence at our disposal, which often comes from secondary accounts or literary reimaginations. ${ }^{1}$ In this respect, poems inscribed on stone monuments offer a unique opportunity to consider how genre relates to the visual and material experience of poetry. $^{2}$

Even within the large corpus of archaic inscriptions, there is no other poem whose visual impact can rival that of the one discovered chiseled into

* Thanks to the organizers of the Berkeley conference and to the participants for their discussion. Nikolaos Papazarkadas and Mario Telò especially offered important feedback. Before the conference, Deborah Steiner kindly shared with me a chapter of her forthcoming monograph that includes a stimulating analysis of the Ambracian monument from a perspective similar to the one presented here (though with different arguments and conclusions). I am grateful to Leslie Kurke for her help with this paper at multiple stages and to Niall Atkinson, Joseph Day, Margaret Foster, Naomi Weiss, and the volume's readers for their comments on earlier versions. Finally, I owe thanks to various people who helped me study and publish the monuments in this paper: Kevin Daly and Ioanna Damanaki at the American School of Classical Studies in Athens, Barbara Papadopoulou of the Ephorate of Antiquities of Arta, the staff at the Archaeological Museum of Arta, and Leonidas Bournias at the Kerameikos Museum in Athens.

1 E.g. Kurke 2012: 220 on choreia: "it is by its very nature evanescent and therefore more or less invisible in the archaeological record."

2 On the materiality of inscription in classical antiquity, see most recently the papers collected in Petrovic, Petrovic, and Thomas 2019. 
the surface of a cenotaph in the modern city of Arta, ancient Ambracia (SEG 41.54OA, 44.463): ${ }^{3}$

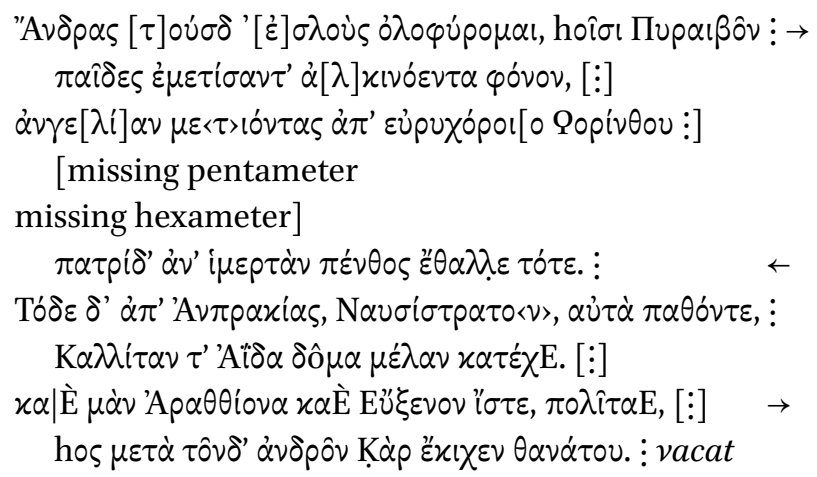

I mourn these good men, for whom the sons of the Pyraiboi devised a painful slaughter,

while they were escorting an embassy from [the Corinthia] with wide dancing places

\section{then in their lovely fatherland grief blossomed.}

And these two from Ambracia, who suffered the same things, Nausistratos and Kallitas the black house of Hades holds back.

And here again, fellow citizens, (you) know Araththion and Euxenos, whom the Ker of death overtook with these men.

The Ambracian monument, usually dated to the second half of the sixth century $\mathrm{BCE}$, is a massive structure, $12.4 \mathrm{O} \mathrm{m}$ long and $2.5 \mathrm{O} \mathrm{m}$ high, built of imposing ashlar masonry made from local limestone (figs. 10.1-2). ${ }^{4}$ It consists of a rectilinear crepidoma, $0.40 \mathrm{~m}$ high, surmounted by five courses of stone, each

3 Ed. princ. Andreou 1986; Bousquet 1992; Cassio 1994; D'Alessio 1995; Day 2007; Randone 2013; Graninger 2014. I follow the text in Cassio 1994: 103, D'Alessio 1995: 26, Day 2007: 30, and Day 2019: 238. While the inscription has received significant scholarly attention, the monument's architecture and the finds within it await full publication. In addition to the preliminary publication of the archaeology of the monument in Andreou 1986, I rely on my own observations of the monument.

4 For the dimensions see Andreou 1986: 425 . 


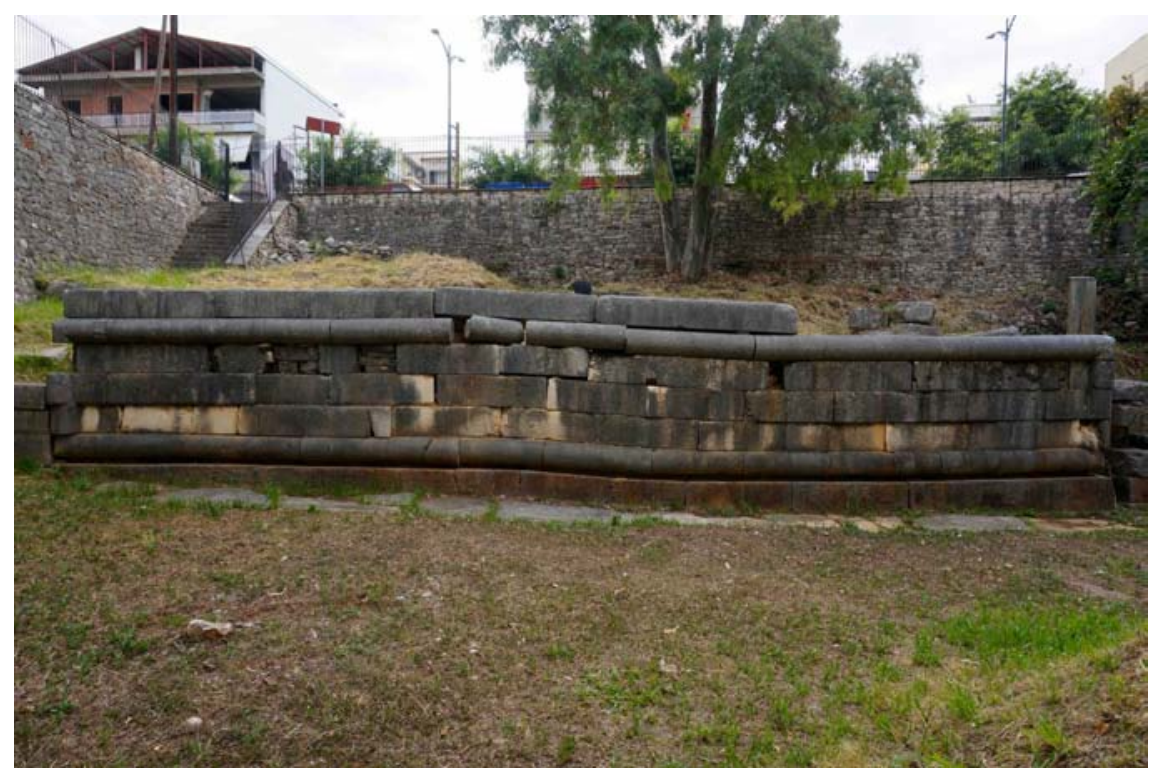

FIGURE 10.1 The Ambracian polyandrion. Second half of sixth century BCE. Ephorate of Antiquities of Arta PHOTO: AUTHOR. COPYRIGHT (C HELLENIC MINISTRY OF CULTURE AND SPORTS

between $0.32 \mathrm{~m}$ and $0.36 \mathrm{~m}$ tall, which are framed by a large rounded torus molding. An additional sixth course of the same height sits on top, more or less at eye level, bearing the three lines of inscription, which, when the monument was complete, ran boustrophedon twice across the length of the façade and once more to its center, just below a cutting on the monument's upper surface for a now-lost stele. ${ }^{5}$

If the monument's size and scale demand to be seen, this is an inscription that demands to be read. The letters are not only unusually large but unusually fine in their carving, generously spaced out and oriented in stoichedon style both horizontally and vertically. The poem itself, originally composed of five elegiac couplets, is the longest surviving example of inscribed funerary epigram of the archaic period, and its language and imagery are among the

5 Andreou 1986: 438. A number of stelai were found during the course of excavation, one of which Andreou (1986: 438-445) associated with this cutting and which is now on display in the Archaeological Museum of Arta. But as Matthaiou (1990-1991) notes, and as my own observations have confirmed, its dimensions are too large. See also Bousquet 1992: 6o5-6o6. The other stelai remain unpublished. 


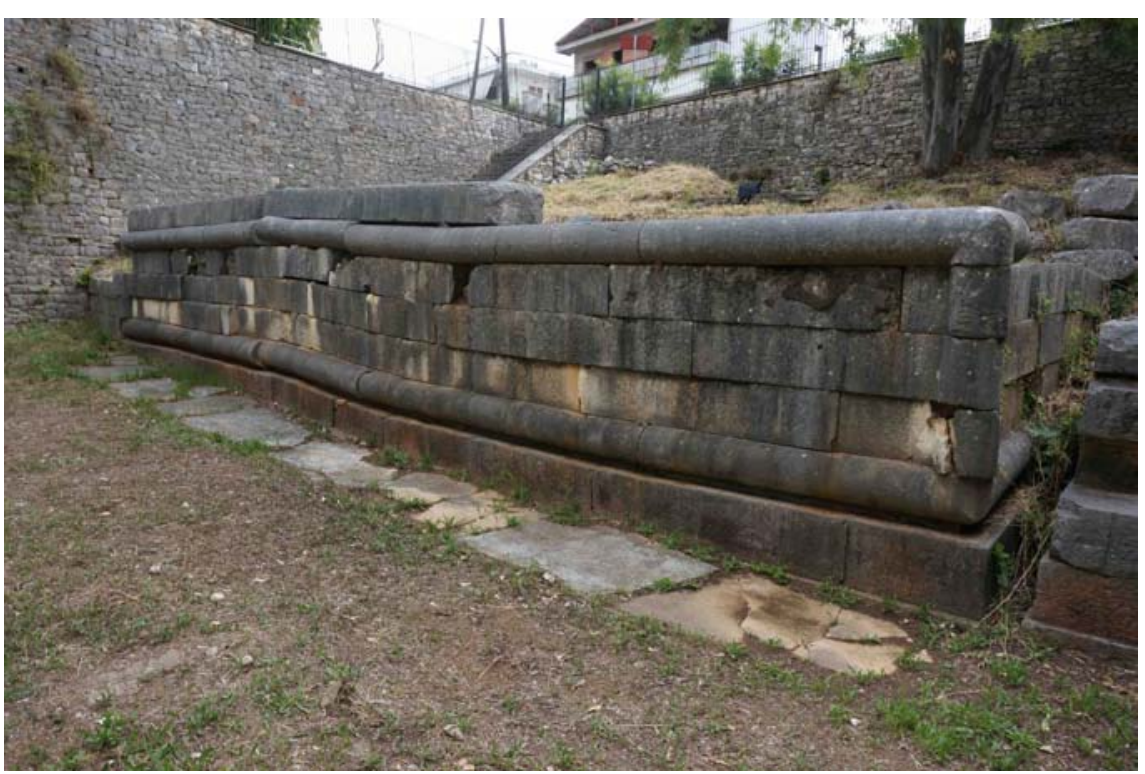

FIGURE 10.2 The Ambracian polyandrion. Second half of sixth century BCE. Ephorate of Antiquities of Arta PHOTO: AUTHOR. COPYRIGHT (C) HELLENIC MINISTRY OF CULTURE AND SPORTS

most sophisticated of poems of this kind. ${ }^{6}$ The combination of monument and poem presents a unique opportunity to experience a relatively complex work of archaic poetry in the same format, in the same location, and as a function of the same monument as it was experienced in antiquity.

Since its discovery, the Ambracian monument has been recognized for its potential to provide insight into how archaic elegy relates to mourning and funerary ritual. ${ }^{7}$ This relationship is usually considered at the level of semantic content, and the Ambracian poem has often been treated as a document of the kind of poetry performed at funerals. In contrast, this paper explores how the monument itself structures a relationship between genre and mourning in order to highlight effects of an elegiac poem that we could not anticipate without access to the monument on which it was inscribed. The monument's elegiac couplets, I will argue, do not record mourning so much as they configure mourning, giving it material shape and form in the here and now. When expe-

6 For more detailed readings of the poem itself, see Bousquet 1992; Cassio 1994; D’Alessio 1995; Day 2007 and 2019; Faraone 2008: 133-136; Randone 2013; Steiner forthcoming.

7 For the debate over the relationship between elegy and mourning or threnody, see Bowie 1986; Aloni 2009. 
rienced as a feature of the monument, elegy - which is to say genre itself - can structure viewers' feelings and emotions, their ability to empathize and mourn, their engagement with their built environment, and, ultimately, their capacity to become citizens.

\section{Elegy and the Structure of Mourning}

The poem opens with a first-person voice-a mourner whose grief tears them apart, casting them between a state of active engagement with the deceased, whom they recognize as still present, and a state of helplessness, of acknowledgment of the absence of the deceased. The dialectic emerges in the very first couplet. The first line states "I mourn these good men," pointing to the deceased as a visible presence within the speaker's time and space. The gesture towards the dead suggests their immediate presence as something visible to the first-person mourner, and so, once we acknowledge this voice, to us as well. And yet, towards what can this deictic actually gesture? Not the bodies of the deceased, since the monument, according to its excavators, is a cenotaph. ${ }^{8}$ And the suggestion that it pointed to the deceased as somehow embodied within the now-lost stele or, even less likely, statues that stood above the monument, is mere speculation. Instead, just as the first-person voice introduces a previously invisible mourner, the deictic at the very beginning of the poem opens up a new form of visual experience, one contingent upon memories and visions of the deceased that continue to haunt the mind of the mourner.

The visual experience so dramatically initiated in the first line is immediately undercut by the second line, in which we learn that "these men" cannot, in fact, be present in any tangible form, because they have been slaughtered while on an embassy from far-away Corinth. Where the deictic in the first line points to the men as persons who are here, present to the extent that they can be mourned, this vivid description of the slaughter emphasizes their inaccessibility, their existence only as corpses, which, as the next line makes clear, are not here in Ambracia, and so cannot, in fact, be pointed towards.

This push and pull between the first and second lines of the couplet is not merely a feature of its semantic content. Instead, it is embedded in the metrical structure of elegy, in which hexameter and pentameter lines are set against one another. In many elegiac poems, form and content are aligned, with the

8 Andreou 1986. This point has been contested by Matthaiou (1990-1991), whose arguments have in turn been rebutted by the excavators (Andreou and Andreou 1988). 
pentameter offering a complement or corrective to the assertion of the hexameter in what Gregory Nagy has called "the supplementary function of elegy." For Nagy, this supplementary function arises from the origins of elegy in the context of lament, where one mourning voice was picked up or supplemented by that of another mourner, leading to a communalizing effect that originated in the very structure of the couplet. Nagy applies this model to the funeral where multiple mourners are present and different laments are heard. Yet the embeddedness of this supplementary function in the generic structure of the couplet itself allows it to generate an experience of grief even outside of the context of a funeral - in the encounter, for instance, between a passerby and a funerary monument that offers mournful poetry governed by the same metrical structure.

In the Ambracian poem, the supplementary nature of the first couplet initiates a pattern that occurs throughout the other remaining lines in which a disjunctive statement pits visible presence of the dead against the poignant reality of their absence. Where the hexameter points to the deceased and so, fittingly, draws on techniques of visualization associated with epic poetry, the pentameter that follows - the overtly nonepic feature of elegy — pulls us back to reality. When we turn to the next complete couplet, in lines 7 and 8 , we see this same structure at work. ${ }^{10}$ The hexameter opens once again with a deictic that gestures towards two more men, Nausistratos and Kallitas, introduced as if present. "Yet the pentameter reminds us that "dark Hades" holds them back, forever out of reach. The use in this context of the verb $x \alpha \tau \dot{\varepsilon} \chi \omega$ ("to hold back," or, in reference to a burial, "to cover") finds a parallel in a fourth-century Attic funerary epigram (CEG 479), inscribed on a stele carved with relief images of a man and a woman: ${ }^{12}$

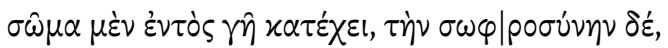

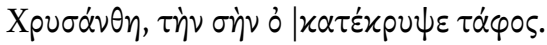

9 Nagy 2010: 20. On the structure of elegy see also Faraone 2008.

10 The second and third couplets are too incomplete to comment on their structure. Nonetheless, the pentameter of the third couplet, with its statement that "sadness blossomed then" ( $\pi \dot{\varepsilon} v \theta \circ \varsigma$ है $\left.\theta \alpha \lambda \lambda_{\varepsilon} \tau \tau^{\prime} \tau \varepsilon\right)$, is entirely consistent with the pattern in its focus on absence, here imagined as not only material but temporal.

11 A different reading of $\tau \delta \delta \delta \varepsilon$, as a genitive singular $\tau 0 \hat{\delta} \varepsilon$, was offered by Matthaiou (19901991: 310). While rejected by most commentators, it has recently been accepted and developed by Graninger (2014: 229-230).

12 Copenhagen, Ny Carlsberg Glyptotek 1595. Clairmont 1993: vol. 2, no. 282b. On epigrams of the fourth century with similar language see Tsagalis 2008: 125 . 
The earth holds back your body within it, but your moderation, Chrusanthe, your tomb has not hidden.

The disjunction the epigram draws between the body that is hidden beneath the earth and the moderation of the deceased that is still visible at her tomb is surely a reference to the relief below-a visual presence that compels us to remember Chrusanthe even as it cannot render her actually present. ${ }^{13}$ Where Chrusanthe's monument is able to compartmentalize what is held back and what is present as if the deceased has been divided up at the moment of her death, the Ambracian poem confuses the two states in a single mourning voice that swings from pointing to fellow Ambraciate citizens as present to announcing that the deceased themselves - not merely their bodies-are held back, out of sight.

The hexameter of the final couplet is even more forceful than the deictics in previous lines, commanding us directly to "know" (or reminding us that we know, if the verb is taken as indicative) the deceased by addressing us as "citizens" and so naming us as participants in the ideological system of the city. ${ }^{14}$ No longer are the deceased visible only to the mourning voice. Instead, we, as citizens affected by their death, are responsible for knowing them, for assuring their continued presence. And yet as we move to the final pentameter, we read that the fate of death has overtaken them, holding them back in the same place as the men named earlier. The object of our cognitive attention and emotional engagement once again slips away.

\section{The Monument's Grief and the Viewer's Pity}

This interpretation of the generic structure of the Ambracian poem as itself articulating grief depends on an interpretive move so far taken for granted: the


line as that of the monument. ${ }^{15}$ In contrast, most scholars, following Albio Cesare Cassio, have placed this first-person voice in the body of the viewer

\footnotetext{
13 For this formulation on another Classical Attic stele (CEG 534) see Estrin 2018: 116.

14 For the ambiguity of the mood of the verb and its relation to the identity implied by "citizens," see Graninger 2014: 231-236. Randone 2013 argues that this couplet is a later addition.

15 Interestingly, the verb occurs here in Ionic rather than local spelling, suggesting that its function is derived from a previously established tradition. On the spelling see Cassio 1994: 104; Day 2007: 40.
} 
who reads the poem. ${ }^{16}$ The text of the poem, in this interpretation, is similar to-perhaps even identical with-the poem that was performed at the funeral of the men named in it. Whoever happens across the monument could take on the mourning voice by reading the inscription out loud, and so reenact the sort of performance, if not the exact performance, that took place at the funeral. When the monument is treated as a record of a prior performance, the meaning of the poem is located in a time and space outside of our encounter with the monument. The monument itself, in turn, is understood as configured so as to reactivate the aesthetics of this hypothetical original performance. ${ }^{17}$

Cassio supports this hypothesis by pointing to other funerary monuments in which a first-person voice expresses distress in the face of death, such as a late sixth-century epigram for the dead Smikuthos inscribed on a stele base from the Kerameikos in Athens ( $C E G_{51}$; fig. 10.3):18

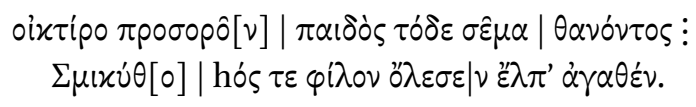

I feel pity as I look at this sema of a son who is dead of Smikuthos who destroyed his loved ones' good hope.

There are important differences—ones that are often overlooked—between the voice of the Ambracian monument and that of epigrams such as Smikuthos'. The Ambracian monument mourns, as we have seen, using the verb

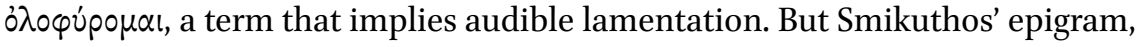
like many others that give voice to the anonymous bystander, expresses a less demonstrative and more distanced emotion: pity (oîx $0 \varsigma) .{ }^{19}$ True mourning, as

16 Cassio 1994; Day 2007: 30-31, 40; Faraone 2008: 133-136; Randone 2013: 34; Steiner forthcoming.

17 Joseph Day has suggested that the reader of the Ambracian poem might "replicate a processional ritual, or perhaps a choral performance" (2007:40). Yet in his overall approach to archaic dedicatory inscriptions, fully developed in his recent monograph (2010), he compellingly argues that the significance of the inscribed monument was only revealed in the dynamics of an encounter with it. Following this account, we can see how the act of reading might have allowed readers to draw on the rhetorical force of an imagined earlier performance, without necessarily replicating one that had actually happened.

18 Kerameikos Museum I 327. See Day 2007: 40-41. For the base, see Kissas 2000: 41-42, cat. A.7.

19 On pity in archaic funerary epigram see Sourvinou-Inwood 1995: 176; Tueller 2010. 


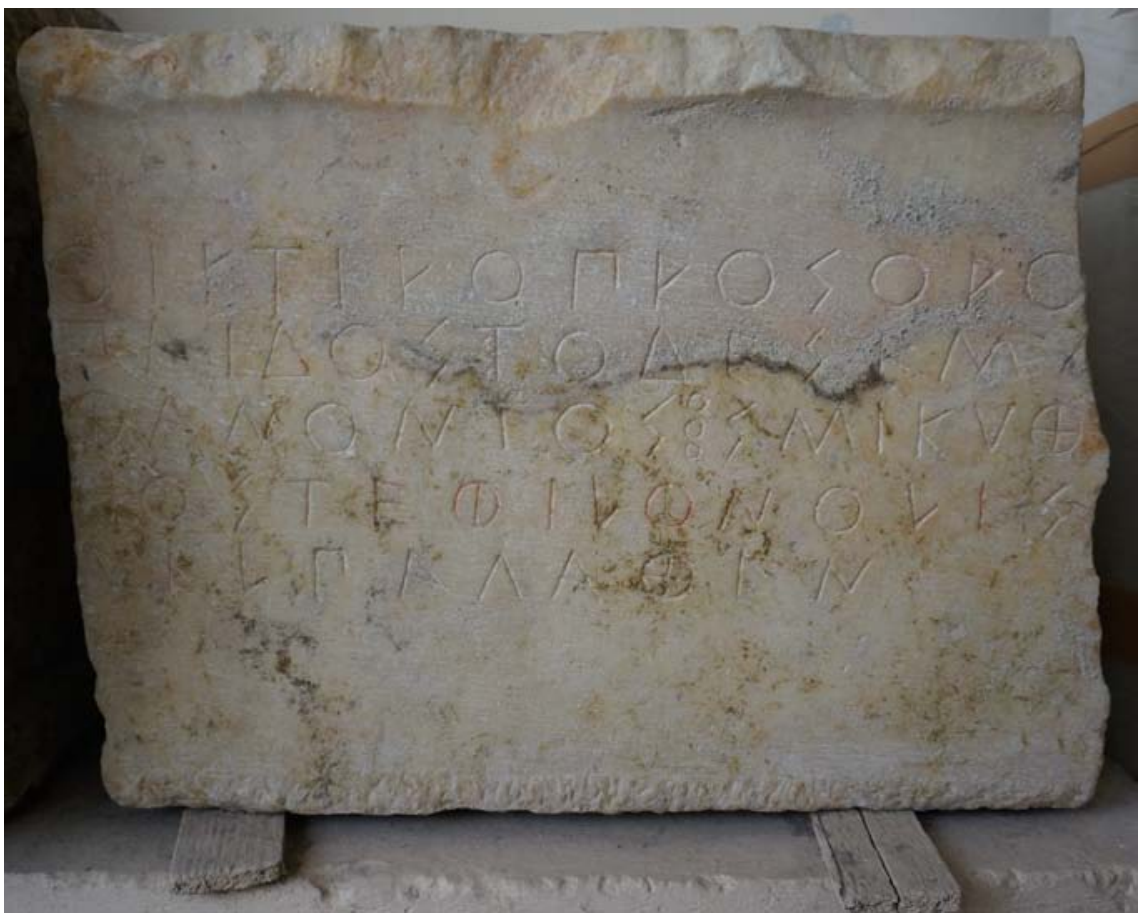

FIGURE 10.3 Inscribed stele base of Smikuthos. Late sixth century BCE. Ephorate of Antiquities of Athens-Kerameikos Museum I 327

PHOTO: E. BARDANI. COPYRIGHT (C) HELLENIC MINISTRY OF CULTURE AND SPORTS

expressed on the Ambracian monument, is reserved in such epigrams for family members - a fact the reader of Smikuthos' epigram seems to acknowledge by pointing to the destruction of their good hopes.

A closer parallel is found on a mid-sixth-century base now in New York but said to be from Athens, whose inscribed epigram for Chairedemos (CEG 14) expresses the grief of a bereaved father using a form of $0 \lambda \circ \varphi v$ po $\mu \alpha:^{20}$

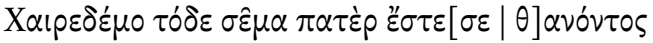

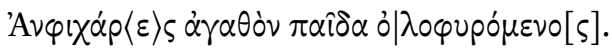

Of Chairedemos, dead, this sema his father

Amphichares set up, mourning a good son.

20 Metropolitan Museum of Art, New York 16.174.6. See Day 1989: 25. For the base, see Kissas 2000: 43, cat. A.9. 
Taken together, inscriptions like those of Smikuthos and Chairedemos make clear a distinction between the trauma experienced by those in mourningfamily directly affected by the death - and the more detached and analytic expressions of pity, reserved for those who empathize with the bereaved but who have not themselves suffered loss. ${ }^{21}$

The distinction between grief and pity affects not only the intensity of the emotional experience but also its object. As an emotion experienced by those who are actually bereaved, grief is directed towards the deceased, as is the case with Chairedemos' father. Pity, in contrast, is generated by and usually oriented towards the monument itself, named as a sema or mnema, as in Smikuthos' epigram, where the speaker is standing before the monument and looking directly at it $(\pi \rho \circ \sigma 0 \rho 0[v]){ }^{22}$ The connection between our pity and our visual experience of the monument as a material object is similarly made explicit in an epigram for a man named Kleoitos (CEG 68):

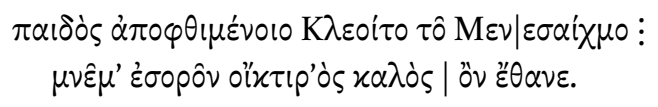

Of a son who died, Kleoitos the son of Menesaichmos, looking on the mnema have pity that he died being so beautiful.

Kleoitos' epigram frames the pity felt by the passerby as a function of looking at the monument (mnema), which, as the cutting in the base indicates, would have consisted of an unusually large stele (fig. 10.4). ${ }^{23}$ The phrase "being so beautiful" indicates that it is the beauty of this stele that provides the measure of Kleoitos' own beauty: he is accessible as an object of pity only insofar as we extrapolate him from the appearance of the monument. And yet the monument's ability to provide access to Kleoitos is undercut by both the content of the epigram and its orthograde configuration on the low and relatively wide base. ${ }^{24}$ The second line break dramatically divides the final phrase of the epigram, ò $x \alpha \lambda$ ò | oै $v$ है $\theta \alpha v \varepsilon$ ("so beautiful | being, he died"), with the first two words at far right and the last two at far left. The physical severing of the phrase

\footnotetext{
21 On this distinction more generally in Greek literature, see Konstan 2001.

22 This is also true of other epigrams cited by Cassio (CEG 470, and Peek 1976: $93 \mathrm{n} .1$ ) as well as $C E G_{27}$ and $C E G_{28}$. An exception is $C E G_{13}$, where the deceased himself is an object of pity. For epigrams that induce the passerby to feel pity, see Tueller 2010.

23 Athens, Epigraphical Museum 10641. For the base and its cuttings see Kissas 2000: 249 cat. C4. Compare the archaic stele of Mnasitheos (SEG 49.5०5, 56.508, 59.466), which speaks in the first person as the "beautiful" ( $\alpha \lambda \lambda_{0}$ ) mnema of the deceased (see Estrin 2016).

The base is $0.735 \mathrm{~m}$ in width (Kissas 2000: 249).
} 


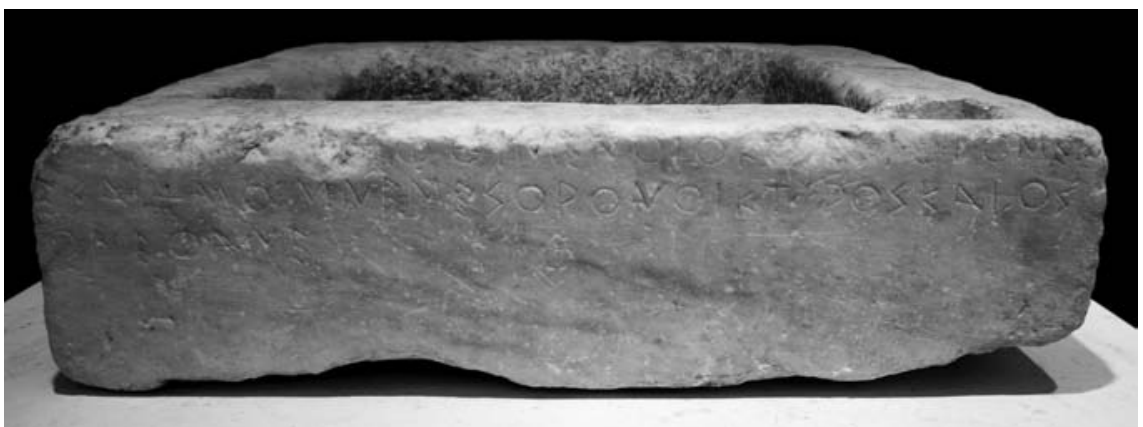

FIGURE 10.4 Inscribed stele base of Kleoitos. Third quarter of the sixth century BCE.

Athens, Epigraphical Museum 10641

PHOTO: AUTHOR/MAGDALENA GLOTZER

materializes the split between the monument's beauty and the man's deatha visual effect that might have, in turn, structured our visual experience of the monument above, including any sculpted or painted image it contained. Yet the epigram suggests that it is not an image of the deceased but the entirety of the monument (mnema) itself that is both the source and the object of our pity.

While pity arises from an experience of the monument itself, the objects of the verbs of mourning - in the Ambracian inscription, the epigram of Chairedemos, and others-are the deceased, unmediated by the monument. If in Smikuthos' epigram "this sema" is the thing that itself triggers pity, in Chairedemos' epigram "this sema" is the material residue, rather than the cause, of mourning. "This sema," in other words, stands between grief and pity, between mourner and passerby: it has been set up by the first in order to affect the second. Understood in these terms, the mourning expressed by the Ambracian monument's voice speaks to a deeply felt personal grief, suggesting that it shares an intimate connection with the deceased that no passerby could establish simply through the act of reading aloud. It is this trauma reserved for the mourner, I argue, that is expressed in the Ambracian poem by the first-person voice that simultaneously points to the deceased and laments their absence.

The monument of Smikuthos and others that articulate pity in similar terms come primarily from Attica, and so pity as an emotion felt by the anonymous viewer has often been seen as a phenomenon particular to that region. ${ }^{25}$ Yet

25 Tueller 2010: 42-46. There are, however, important exceptions, such as an early fifthcentury monument from Sinope (CEG $174 \mathrm{~B})$ and a Hellenistic one from Amphipolis (CEG $724)$, suggesting a wider spread both geographically and chronologically than is generally acknowledged. 
even if the formulaic expression of pity found in archaic funerary epigram originated in Attica, literary evidence from the archaic period upholds a broader cultural distinction between a mourner's grief and a stranger's pity-a distinction between different forms of emotional behavior that extended beyond Attica and of which the language in Attic epigrams is merely an expression. ${ }^{26}$ To return to Smikuthos' epigram, while it contrasts with the Ambracian poem in the identification of the first-person voice, they are linked at a more structural level by their exploration of grief through the supplementary function of the elegiac couplet - through a hexameter that opens up a visual spectacle that is subsequently undermined in the pentameter.

In Smikuthos' epigram, the first line asserts the physical presence of the monument, which is pointed to with a deictic marker, and the emotional presence of the viewer, who offers pity in the first person. The second, in contrast, describes what is absent: the good hopes of Smikuthos' family destroyed by his death. These good hopes were presumably not anticipated by the viewer who never knew Smikuthos, and so reference the family's grief that is distinct from the viewer's pity. The very structure of elegy, in other words, is able to suggest analogies between the different emotions of the bereaved family member and the pitiful passerby by formalizing the conflicting experiences of presence and absence that arise in the face of death.

If the voice of the Ambracian monument that mourns in the first person does not immediately become our own, instead it initiates an encounter with a monument that itself mourns. This capacity for monuments to mourn is clear from other funerary epigrams, such as a six-line inscription on a monument for Anaxilas set up in the Athenian Kerameikos (CEG 58), one of the longest preserved inscribed epigrams from the archaic period after the Ambracian poem: ${ }^{27}$

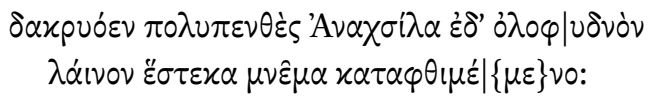

26 There has been unfortunately little overlap between the scholarship on pity in funerary epigram and the numerous studies of pity in Greek literature and culture that have appeared in recent years, such as Kim 2000; Konstan 2001; Sternberg 2005, 2006; Munteanu 2012. An exception is O'Sullivan 2008. At the same time, several recent epigraphic studies address the emotional nature of the experience of reading inscriptions in more general terms: Tsagalis 2008; Day 2010; Chaniotis 2012.

27 Athens, Kerameikos Museum I 388. For the base see Kissas 2000: 62-63 cat. A.29. For the length of these inscriptions see Bowie 2010: $361-363$. More generally on monuments from the archaic period that speak and/or mourn in the first person, see Christian 2015: 28-45, 141-144. 


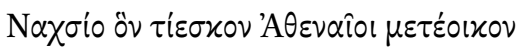

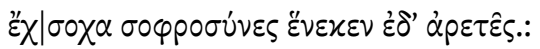

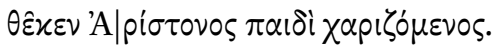

Tearful, exceedingly sorrowful, and mournful

I stand here as a stone mnema of the deceased Anaxilas,

a Naxian whom the Athenians honored as a metic

especially on account of his good character and excellence.

Timomachos set me up over him having performed a reverent funeral honor,

thereby gratifying the son of Ariston, who died.

Using an adjectival form of the same verb of mourning found on the Ambracian

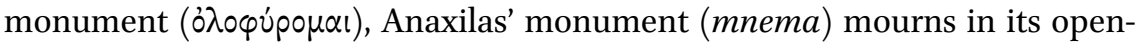
ing hexameter, and even sheds tears. Yet the following pentameter consists of images of static stone and death, and the first-person voice goes on to explain how, as a stone monument, it is something that has been set up as a funeral honor. There is no ambiguity here: this is a mourning block of stone, a fullyformed social agent, occupying the same space as us, but caught in a paralytic state of lamentation. The monument's abrupt transition from describing its

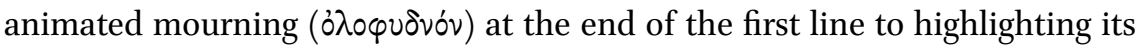
stone materiality ( $\lambda \dot{\alpha}(v \circ v)$ at the beginning of the next once again enables it to embed this disjunctive emotional state in its very generic structure. The tension between the monument's stone materiality and sense of agency would have been simultaneously acted out by the now-lost statue that once stood above it, which was most likely a kouros - a monument that is simultaneously alive and inanimate, mortal and never-aging, and that, as epigrams on bases of other kouroi testify, demands our pity. ${ }^{28}$ Informing both the epigram and the statue, this tension between the monument's materiality and its capacity for animation is at the heart of how it communicates the pain caused by death.

28 The epigram for the kouros monument of Kroisos (CEG 27) famously demands pity. Richard Neer has remarked on the relationship between the formal appearance of a kouros and mourning, arguing that the "pose of a kouros is not a 'mere' formal device, but the means by which the statue expresses its peculiar temporal predicament: that of mourning" (2010: 42). Anaxilas' base is sometimes assumed to have supported a seated statue, but parallels for inscribed blocks of its size and proportions much more frequently belong to the kind of stepped base that supported a kouros; see Kissas 200o: 62-63, cat. A.29. 
We can see the distinction between mourning and pity at the site of the funerary monument at work in a passage from the Iliad where Achilles' horses - the only animals in the Iliad endowed with human qualities such as speech-encounter the corpse of Patroclus and begin to mourn. ${ }^{29}$

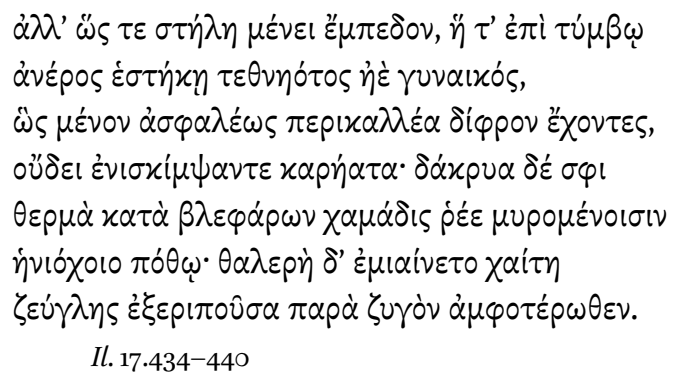

... but still as stands a grave monument which is set over the mounded tomb of a dead man or lady, they stood there holding motionless in its place the fair-wrought chariot, leaning their heads along the ground, and warm tears were running earthward from underneath the lids of the mourning horses who longed for their charioteer, while their bright manes were made dirty as they streamed down either side of the yoke from under the yoke pad.

Trans. R. LATTIMORE

The metaphoric comparison of the horses to a stele underscores not simply their lack of movement, but the channeling of all their emotional and affective engagement towards Patroclus. As in Anaxilas' epigram, the descrip-

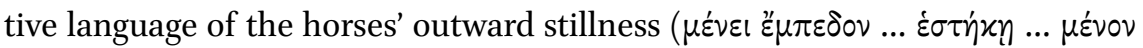
$\left.\dot{\alpha} \sigma \varphi \alpha \lambda \varepsilon^{\prime} \omega \varsigma\right)$ contrasts sharply with their inner emotional turmoil—a turmoil so potent that it overwhelms their solid, unmoving forms, staining their bodies with tears. Like the structure of the elegiac couplet, the paradoxical ontology of the weeping stone monument serves to formalize the traumatic effects of grief. Where grief brings the stone monument of Anaxilas closer to life, it works on the living horses from the opposite direction, bringing out the monument-like qualities of sentient beings. ${ }^{30}$

29 For a comparison between the movements of the viewer of the Ambracian monument and Achilles' horses in this passage, see Steiner forthcoming.

30 For related observations on the blending of animate and inanimate in Homeric poetry, see Purves 2015 . 
Just as Anaxilas' monument calls out in its grief to those who pass by it, so too do the horses attract the attention of a bystander:

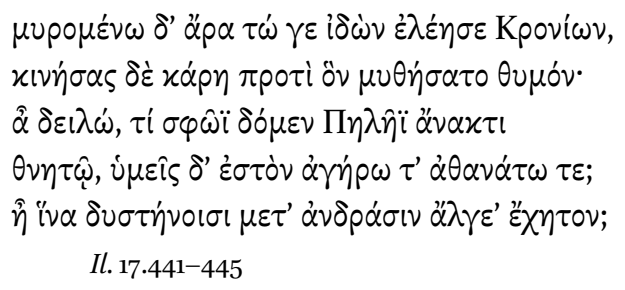

As he watched the mourning horses the son of Kronos pitied them and stirred his head and spoke to his own spirit: "Poor wretches, why then did we ever give you to the lord Peleus, a mortal man, and you yourselves are immortal and ageless? Only so that among unhappy men you also might be grieved?"

Trans. R. LATTIMORE

Where the true mourners are assimilated with the monument itself, Zeus, as an onlooker not directly affected by Patroclus' death, feels pity instead. ${ }^{31}$ The language Zeus uses to describe his pity attends precisely to the tensions we find in inscribed funerary epigram, suggesting that the metaphoric comparison of the horses to a stele focalizes Zeus' own experience as viewer. The epigrams of Smikuthos and Kleoitos generate pity by asking the viewer to attend to the gap between the material presence of the stele above and the absence of the deceased in the lives of those who erected the monument. In the same way, Zeus explains that his pity arises from the tension he observes between the horses' immortality and their experience of grief-an emotional experience normally reserved for mortals. That the horses appear stele-like in this moment suggests that it is precisely this tragic tension between the existence of the stone monument as a permanent, immortal, and unfeeling object, outside of the realm of human experience, and its status as a social agent endowed with human emotion that engenders pity in the viewer. It is this tension that is built into the Ambracian poem at the level of genre.

31 A similar episode occurs at Il. 16.1-5, where the weeping Patroclus is described as looking like water streaming over rock-a sight that inspires pity in Achilles. See Christian 2015: $145^{-146 .}$ 


\section{Movement and Agency}

What is the status of a monument that mourns? It is certainly not identical to that of a human mourner, and my claim is not that the monument has somehow come to life or taken on human agency. Rather, the mourning monument draws us into an intersubjective, empathetic relationship with what makes it nonhuman: its stone materiality, its durability, its monumentality, its embeddedness in its surrounding landscape. In so doing it puts into question a strict binary between human and thing, exposing mourning as a state that affects both. ${ }^{32}$ When after the initial cry grief reappears in the poem, in line 6 , it is as something that "blossoms," overtaking the beautiful fatherland of the men who died as if growing from the earth. Like the description of Achilles' horses as inert yet stained with their own tears, this image of mourning as emerging from the inanimate of its own accord compels us to look for grief not only in the metrical structure of the poem but in the very materiality of the monument. The result is a tension between the monument's materiality and its animation that amplifies the same tension inherent in the structure of elegy through which it expresses its grief.

The strategies a monument could employ to suggest an interplay between its inscribed epigram and its materiality are perhaps more obvious in the case of those that were decorated with figurative elements. The viewer of the monument of Smikuthos, for instance, encounters an epigram inscribed in five lines of clear, carefully carved letters on a base that supported a marble stele (see fig. 10.3). As we read each line downwards, our eyes move from the stele above - now lost but likely painted or carved with a vivid, life-size image of a young man like Smikuthos himself - towards the ground where his dead body lies. In the process, we move from our own emotional reaction to what we see in the first line ("I feel pity as I look at ...") towards the loss that haunts the bereaved family. The very generic structure of the elegiac couplet here helps integrate the work of the epigram into a more holistic visual and emotional experience from which it cannot be separated.

Instead of figurative imagery, the Ambracian monument uses the configuration of its stones and of the poem across its face to activate the structure

32 Compare Jane Bennett's observations that material things are not static and immobile in binary opposition to humans, but rather their "rate of speed and pace of change are slow compared to the duration and velocity of the human bodies participating in and perceiving them. 'Objects' appear as such because their becoming proceeds at a speed or a level below the threshold of human discernment" (Bennett 2010: 58). We might say that genre makes the "becoming" of the monument discernable as such. 
of elegy. The integral role of the monument's material presence is established through its ability to control readers' movements, with the layout of the inscription requiring a reader to walk a distance of almost $30 \mathrm{~m}$, crisscrossing the monument's façade twice. ${ }^{33}$ Those who see the inscription as a record of a performance interpret this choreographed path as recreating, either symbolically or literally, the funeral procession that might have accompanied the poem's original performance, before it was inscribed. Yet rather than remove us to an imagined earlier performance, our encounter with a mourning monument compels us to directly confront the built structure before us, from which the voice emerges. As we finish reading, we are left standing almost directly in the center of the monument, surrounded by it on either side, our bodies aligned with the stele above.

This act of walking makes us acutely aware of its sheer physicality and draws our eyes towards details of its visual configuration. ${ }^{34}$ But it might do much more than that. For in retracing our steps and submitting the animation of our own bodies to the control of the monument, we reciprocate and amplify the animate presence of the first-person voice in a way that coincides with attitudes towards the agency and vitality of nonhuman matter as expressed in early Greek literature, such as the passage of the Iliad discussed above, as well as in pre-Socratic philosophy and scientific writing. ${ }^{35}$ Thales' understanding of magnets, as recorded by Aristotle, provides a way of thinking about this relationship between motion and agency: "Thales, too, seems, from what they record, to have supposed that the soul was something motive, since he said that the stone [i.e., the magnet] has a soul because it moves iron" (trans. Collins). ${ }^{36}$ If a stone appears to have a soul when it causes something else to move, animation is not an inherent property of stone, but a quality that

33 Day 2019: 241-242.

34 This emphasis on the material structure of the monument is made explicit in some inscribed epigrams, such as that of another large-scale archaic funerary monument, the tomb of Menekrates, perhaps dating as early as the late seventh century, on Corfu, another Corinthian colony ( $C E G$ 143). The circular tomb was ringed around its circumference with six lines of hexameter that describe how it was constructed through the grief of the deceased's family and community, linking the materiality of the monument and the grief that occasioned it for the viewer who walked around it to read the poem. See Bousquet 1992: 6o5; Bowie 2010: 310.

35 See, for instance, Alex Purves' account of "the lively and permeable boundary between human and nonhuman in early Greek epic, one that suggests that objects can have their own life form, their own energy, vitality, and even creativity" (Purves 2015: 75).

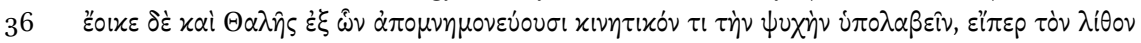

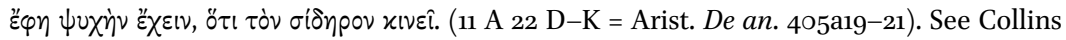
20०3: $37-38$. 
emerges as a function of the presence of the thing moved. By recognizing that a stone monument has caused our bodies to move, we not only recognize its animate potential, but the materiality of our own bodies. Inherent in the fabric of the monument yet only perceived through the embodied act of reading, genre provides a mechanism for awakening what Thales might call the monument's soul. $^{37}$

Acknowledging the authority of the monument encourages us to see the same tension between animation and immobility-itself an elaboration of the disjunction between presence and absence we first saw in the structure of the elegiac couplet-in the configuration of the inscription. The text we read, carved in unusually careful stoichedon, forms a visually consistent pattern aligned with the size and orientation of the horizontal blocks that make up the monument. ${ }^{38}$ As we move across its front, abstract letterforms transform into a unified poem, bringing forth the animate first-person voice.

But just as it gives structure to the content of the poem, genre reconfigures this regulated appearance. Tricola have been carved between the hexameter and pentameter lines, in the gap between the regularly spaced letters. These give visual and material presence to the tension between presence and absence - and the grief caused by that tension - that is embedded in the poem's very genre. ${ }^{39}$ We can see in the break between the third and fourth couplets, for instance, how a tricolon marks a gap between the visually similar words $\tau \dot{o} \tau \varepsilon$, the temporal adverb meaning "then," pointing in the pentameter to mourning in the past at the end of the third couplet, and $\tau \delta \delta \varepsilon$, a deictic adjective meaning "these two" which opens the following couplet by pointing to two deceased men (fig. 10.5). As we read the poem, the tricolon breaks up the text at metrical, semantic, and visual levels, giving material weight to the disjunctive effects of the poem by making them visible on the surface of the stone itself. The mourning voice and its disjunctive effects only emerge by upsetting the regularity and solidity of the poem as a visual feature of the monument.

This tension between the visual unity of the text and its fragmentation through genre is amplified by the configuration of the thick molding carved in a

37 Considering the wall-like qualities of the monument as discussed below, we might compare Thales' account of the stone's soul with the description of Ajax in the D scholion on

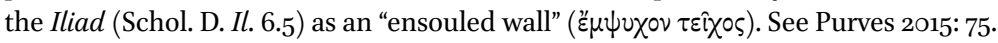

38 On the high quality of the carving see Bousquet 1992: 597-599, 6 o4.

39 Tricola are lacking after lines 8 and 9 -one of the features that has led Randone (2013: 45) to argue that the final couplet is inscribed by a different hand and is possibly a later addition to the monument. 


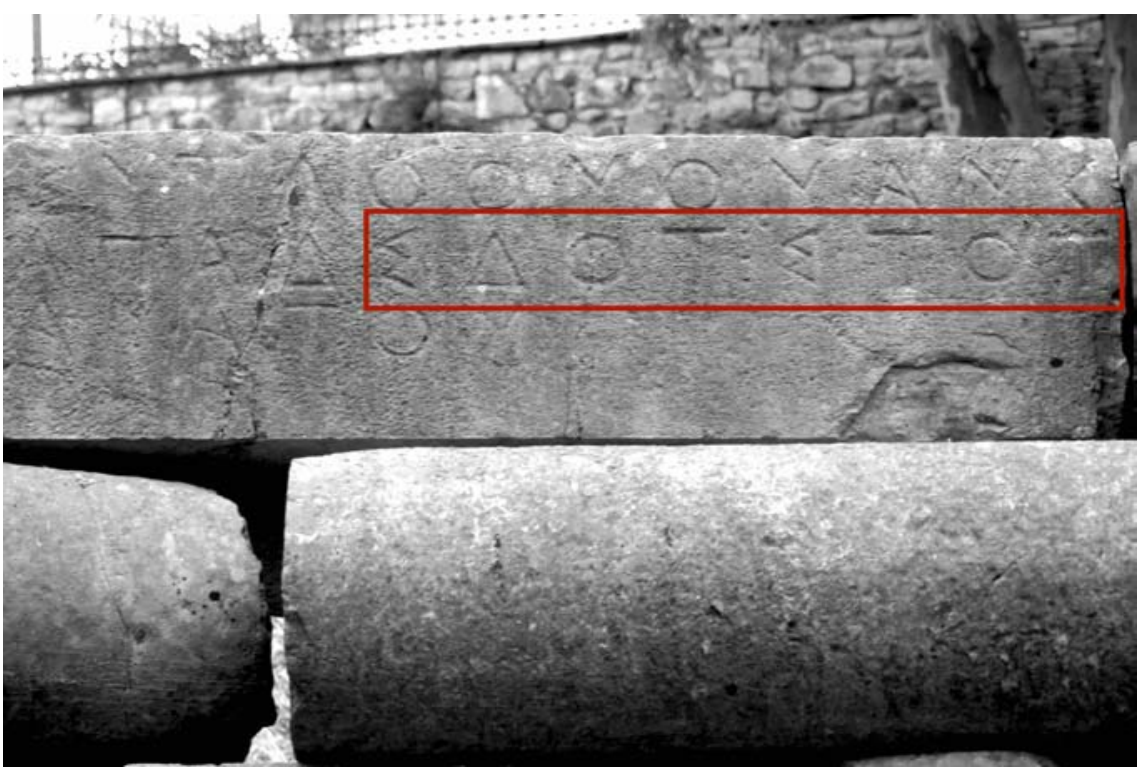

FIGURE 10.5 Detail of inscription of Ambracian polyandrion. Ephorate of Antiquities of Arta

PHOTO: AUTHOR. COPYRIGHT (C HELLENIC MINISTRY OF CULTURE AND SPORTS

deep, convex torus around the edges of the monument. ${ }^{40}$ The gap between the strict right angle of the crepidoma's edge and the rounded curve of the molding running above it creates a line of shadow that makes the bulk of the monument appear to sit on top of - rather than extend out of - its base. It is this structure, encased by the molding, that in turn supports the uppermost course of stones on which the inscription is carved.

Even though the monument follows the cuboid structure of its base, the molding gives it a shape and form of its own. Running both up and down, from both left and right, the molding follows the orientation and regularity of the inscribed letters and the viewer's movement across the façade. Particularly unusual is the upright orientation of the molding at the outer edges, where vertical stretches join the lateral ones to complete a rectangle across the front surface, surrounding the recessed inner face (see fig. 10.2). This formation enables viewers to follow the molding not only horizontally but, at the edges of the monument, vertically as they move their eyes downwards and backwards according to the boustrophedon layout of the inscription.

40 On the molding see Andreou 1986: 426 . 
Complex planning was required to give the appearance of a unified rectangle across the monument's face. The horizontal sections at the bottom and top constitute a discrete course of stones, with their outer edges above and below corresponding with the edges of the blocks from which they are formed. In contrast, the vertical sections of the molding emerge from the corners of the blocks at the ends of the second, third, and fourth courses. In this sense, their orientation works against that of the horizontal ashlar blocks of the monument - a virtuoso display of craftsmanship that would have wasted a significant amount of stone. The interplay of the molding with the flat surface it encompasses continues around the sides, so that vertical sections of the molding trace three-quarters of a cylinder that joins two perpendicular faces. The four extremities of the façade mark where not two but three stretches of molding converge from different angles, creating something like an exoskeleton-an autonomous plastic form that contrasts with the flat, horizontal blocks from which it is, in fact, materially formed.

The patterning is deceptively simple, but the effect depends on strategies of negotiating the relationships between parts and the whole that are hallmarks of archaic sculptural practice-what Richard Neer has called "joining." ${ }^{41}$ In archaic sculpture, for Neer, representations of physical bodies and visual images emerge by integrating and synthesizing discrete sculptural flourishes through practices of carving and viewing. So, for instance, a sculpture might be articulated with individual anatomical elements - a pair of eyes, a nose, a chin, and so forth - which come together to form a representation of a human face only through the eyes of a viewer. A viewer who visualizes the molding of the Ambracian monument as a continuous entity, surrounding and moving across the surfaces of the monument, must synthesize distinct stone blocks in a similar fashion. ${ }^{42}$

The viewer's experience of negotiating between how the molding is visualized (as something independent of the interior of the monument) and how it has been constructed (as configured from the monument's blocks) can be understood as operating according to the same disjunctive structure as the poem. Reading the inscription requires us to disrupt the regular stoichedon pat-

\footnotetext{
41 Neer 2010: 40-46.

42 To adopt the theoretical language of Whitney Davis' recent work on visuality (2017), we might say that a viewer will pictorialize the monument- that is, understand its visual coherence as an intended aspect of its configuration —only from particular standpoints in time and space. Because these standpoints constantly shift as the viewer reads the epigram and moves across the monument's façade, any visualization of the monument is inevitably unstable and its appearance is continuously renegotiated.
} 
terning of the text according to the inherent tension of elegy. Simultaneously, following the molding with our eyes compels us to reconfigure the monument itself according to new structures, joining some blocks together to follow its winding form while breaking up others into discrete elements of flat surface and molding. The transformation of distinct blocks into composite forms offers the possibility of opening up new realities, of encountering something that is not actually there, as in the hexameter lines. But seeing only the blocks of stone in themselves means seeing what is here and now, as in the pentameter lines, and so acknowledging the form traced by the molding as marking out an absence as much as a presence. The carving of the monument and the articulation of its molding, in other words, not only provides a visual formalization of our own movements, changing directions with us as we transform stone blocks into a mourning voice, but gives material substance to the mourning voice we encounter in the poem.

\section{A City That Mourns}

The interpretation of the monument so far presented indicates that it was configured in every aspect for a viewer who was not already a mourner-a viewer who perhaps had no prior knowledge of the slaughter commemorated by the monument. As we have seen, the couplets of the poem create a gradual buildup of intensity for the viewer who reads them and moves across the façade, culminating in the strong political overtones in the final couplet, where the viewer is addressed in the plural as "citizens" and asked to know the deceased directly. If the initial lines invite us to confront the disjunctive structure of mourning from an outsider's perspective, by the time we reach this final couplet we are asked to experience them as if we are ourselves, in a sense, bereaved. ${ }^{43} \mathrm{~A}$ private grief, such as the one expressed on the monument of Smikuthos, generates pity. But the Ambracian monument instantiates a public loss, its anonymous first-person voice not that of a bereaved parent suffering an individual tragedy, but that of a monument that forms part of the built landscape of the city we ourselves inhabit. ${ }^{44}$ The passerby who reads the monument moves from an

43 Even if Randone 2013 is right to argue that this couplet is by a different hand than the first four, it is close enough not only in its overall appearance but also in its disjunctive structure that any reader would have experienced it as continuing and amplifying the effects of the first four couplets. For an argument that the five couplets form a unified structure, see Faraone 2008: 133-136.

On public elegiac epigram see Aloni 2009: 181-182. 
encounter with a mourning voice to a submission to that voice's-and so the city's - physical, emotional, and social control. The eventual transformation of our emotional engagement from pity into mourning is the same process as our transformation from stranger into citizen. ${ }^{45}$

In its presentation of an individual mourning voice as assimilating its grief into the broader civic community, the Ambracian poem is similar to other archaic elegiac poems that attempt to reconcile the concerns of the city with the mutability of the fate of the individual. ${ }^{46}$ The speaker of Archilochus fragment 13 , for instance, explains to his fellow symposiasts the difficulty of engaging in civic affairs or festivities when we are afflicted by grief. ${ }^{47}$ The pain of grief is difficult to put aside, as he says:

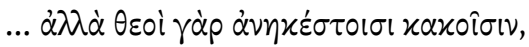

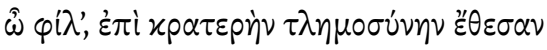

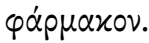

ARCHIL. fr. 13 W, $5^{-7}$

... but the gods, over our incurable misfortunes,

my friend, have set up strong endurance

-a magical antidote.

Grief does not go away—its effects are literally without cure. And yet the gods temporarily mask this sorrow by placing a sort of protective shell over it that works through its strength, its endurance, and its magical properties. ${ }^{48}$ The materiality of the cover is underscored by the use of the verb हं $\pi \iota \tau^{\prime} \theta \eta \mu \iota$ ("to place on top"), a verb commonly used in funerary epigrams - as, for instance, in Anaxilas' epigram discussed earlier-to describe how the visible monument has been placed over the corpse. ${ }^{49}$ Where in the sympotic context Archilochus can use this cover to put aside mourning and take up festivities, the stone monument works from the other end, pockmarking its smooth, solid surface with traces of mourning. Elegiac poetry, in both the sympotic and the cemetery con-

45 We find a similar transformation from pity to mourning in the epigram on the base of an archaic funerary monument from Attica inscribed for Tetichos (CEG 13).

46 For comparison of the language of the poem with elegy from other contexts see Cassio 1994; Faraone 2008: 135; Bowie 2010: 322, 356.

47 See Steiner 2012a.

48 See Steiner 2012a: 34 .

49 For this use of ह̇ $\pi \imath i \theta_{\eta} \mu l$, see also $C E G_{32}, C E G_{35}, C E G_{53}, C E G_{138}$, and $C E G_{169}$. 
text, works to make individual grief resonate more broadly by giving mourning a structure that can unite singer and audience and integrate grief into civic culture as a shared experience.

Only when we consider the Ambracian monument as a function of that civic culture can we evaluate the impact of its politicization of mourning. The monument forms part of the city's largest cemetery, located along the most important road between the port and the city. ${ }^{50}$ This road was monumental in scale, ranging from $10 \mathrm{~m}$ to $12 \mathrm{~m}$ in width and paved in part with large stone slabs. Excavations of sections of this road have revealed three-sided funerary enclosures ranging in date from the archaic to the end of the Roman period, a number of them likewise fronted with impressive built walls marked with stelai and rivaling the polyandrion in size and scale.

Apart from its inscription, what distinguishes the polyandrion from other funerary enclosures is the fact that it is a cenotaph for a group of men not linked by family ties, but by their sacrifice for their city. Where the other funeral plots contain numerous inhumations and vessels for cremated remains, the polyandrion, according to its excavators, contained no burials contemporary with its construction. ${ }^{51}$ The walls, in this sense, are not functional, and do not create an interior space-indeed, in contrast to the smooth outer surface of the stones, on their inside faces they are left roughly carved and unfinished. Instead, they are closer to the defensive walls built around the city of Ambracia itself in the archaic period, constructed from blocks that are likewise commonly dressed on the outside but not on the inside, and filled with rubble - walls made to appear as solid when they are not. ${ }^{52}$ The monument is built, in other words, as an empty shell, something whose meaning is contained neither only in its visible appearance nor in what it contains inside, but instead in the dialectic interactions between finished exterior and empty interior-between what we can point to and what is held back. ${ }^{53}$

At the level of civic performance, close parallels between how the materiality of the monument enacts the rhetorical effects of its inscribed poem can

50 For the location of the monument within the city and cemetery, see Angeli 2013.

$5^{1}$ The excavations have not been fully published and unfortunately it is impossible to know at the moment which, if any, monuments predate or were contemporary with the polyandrion. See Angeli 2013 for an overview.

$5^{2}$ On the fortification walls of Ambracia, see Angeli 2013: 179-180.

53 Compare the role of the Achaean wall in Homer's Iliad which, as James Porter (2011) and Karen Bassi (2016: 40-63) have separately argued, moves between fact and fiction, between the visible and the invisible, to construct a layered epic past through the material present. 
be found in choral poetry. ${ }^{54}$ In a fragment of Pindar (fr. 194.1-3 Maehler), for instance, the chorus describes itself as stamping out a foundation for its songs and exhorting itself to "build a wall ( $\tau \varepsilon \varepsilon \chi \zeta \zeta \omega \mu \varepsilon \nu)$ that serves as an adornment

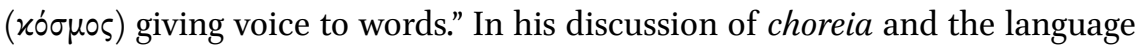
of craft, Timothy Power highlights how in this passage "the chorus is notionally constructing itself through its very performance as an intricately crafted thing of beauty ... that yet has voice. ${ }^{55}$ Like the mourning voice embedded in the Ambracian monument, the chorus conceives of itself as something between human and nonhuman, something that combines the solidity and materiality of a built structure with the animation of a human being. The material foundations of the chorus' performance not only ensure its continued presence, but, as Power argues, articulate the political character of choreia, which emerges as a foundational act that allows the city to take form. Embedding its speaking voice not simply in a crafted chorus but in an actual material construction - an elaborate walled adornment to the city-only enhances the Ambracian poem's ability to unite its citizens in a common emotional experience.

As Power and others have shown in recent years, choreia often draws explicitly on the language of craft to achieve this sense of civic unity. ${ }^{56}$ Such imagery serves to heighten the visual and emotional effects of performance by giving a formalized structure to the relationship between audience members and choreuts. The stone Ambracian monument works in similar terms, drawing us towards it through its ability to speak and make us move. So, for instance, the monument's ability to open up new forms of visual experience through its first-person voice and its use of deictic gestures is analogous to how AnastasiaErasmia Peponi has described Alcman's first Partheneion, where deixis and movement likewise take hold of and extend the audience's gaze from what is materially present into a realm of psychic imagination. ${ }^{57}$ As in the Ambracian poem, where each surviving couplet presents a new pair of men, the Partheneion introduces young girls sequentially, pointing to them with demonstratives and deictics and asking the audience to visualize them through color-

54 Steiner forthcoming likewise explores the relationship between the monument and choral performance.

55 Power 2011: 96.

56 Peponi 20o9; Power 2011; Kurke 2012, 2013a; Neer and Kurke 2014; Steiner 2014a: 31-33, forthcoming; Weiss 2016. In particular, the notion of "joining" outlined above in terms of the monument's construction finds close parallels in Kurke's exploration of the relationship between craft and choreia (Kurke 2012: 230, 2013a: 156-157). More generally on the relationship between aesthetics and the architecture of both built monuments and poetry in ancient Greece, see Porter 2010: 453-523.

Peponi 2004, 2015. 
ful metaphors and imagery. Where these effects serve to transform the visual experience of the dancers who are present into something visionary and dream-like, in the Ambracian monument, as we have seen, such possibilities are undercut almost as soon as they are presented through the structure of elegy. Nonetheless, the comparison highlights the rhetorical effectiveness of the Ambracian monument's voice as constructing the monument itself as a vibrant material presence with which we can empathetically engage.

The Ambracian monument's control of the viewer's body is suggestive of the effects of chorality that make use of physical attraction and kinesthetic movement to create bonds between audience and performers. In a recent discussion of choral mimesis, Leslie Kurke points to a passage in Plato's Ion (533d-536d) where Socrates makes the analogy between the individual involved in a poetic performance and an iron ring in a chain attracted to a magnetic stone. ${ }^{58}$ The magnetic stone in this metaphor is the divine source-the Muse-that does not simply inspire but kinesthetically attracts the poet. This attraction initiates a literal chain reaction of rings physically linked to one another and drawn together through the magnetic force imparted from one to the next. If, following Thales, the physical pull of the stone monument that makes us move is similar to that of a magnetic stone that moves iron, we can see how our movements as we read the inscription draw on the same structures of agency and efficacy as choral performance.

For Kurke, this understanding of choreia as operating according to the logic of magnetic attraction speaks to its ability to generate an "intersubjective fusion and merging of chorus and audience." ${ }^{59}$ In her account, "[i]nsofar as the chorus serves to represent and draw in the whole community, its bodying forth of magical unity animated by a higher power is closely linked to moral effects: the affirmation of proper communal (civic) order as part of a proper, hierarchized cosmic order."60 In the context of choreia, as in the context of inscribed monuments dedicated to deities, such "intersubjective fusion" between the chorus and its material environment serves as a mechanism to connect its members with the divine. ${ }^{61}$ But the goal of the Ambracian monument is to link us with the men whose slaughter it commemorates-a connection that can never be fully achieved. In the Ion, Socrates describes how each element - whether poet, audience member or choreut — is "possessed" or "held" ( $\kappa \alpha \tau \varepsilon \chi \varepsilon \tau \alpha l)$ by the next in the magnetic chain. In the Ambracian poem,

\footnotetext{
$5^{8}$ Kurke 2013a: $15^{1-15^{2}}$.

59 Kurke 2012: 231.

6o Kurke 2012: 231.

61 On the ability of inscribed epigrams to connect a reader with a named deity, see Day 2010.
} 
in contrast, the same verb $(\kappa \alpha \tau \dot{\varepsilon} \chi \mathrm{E})$ is used to describe how the dead, even as they are pointed to, are held back from us in Hades. ${ }^{62}$ Even as it draws on aesthetic devices also found in choral performance, the disjunctive structure at the heart of the Ambracian monument complicates any sense of assimilation.

Thinking through choreia allows us to appreciate how the monument questions a binary between human and nonhuman not just by asserting its own agency, but by compelling the reader to confront their own materiality. In reading the poem we adopt the same disjunctive structure that configures the entire monument, from the shape of its stones to the genre of its inscribed poem. Our mourning makes us stone-like agents whose devotion to the deceased constricts our bodily independence. Yet the more we adopt the structure of the mourning monument, the more deeply we internalize its inherently broken relationship with the deceased. For the mourner-whether made of stone or of flesh and bones - a sense of emotional and even visual proximity never transforms into a true connection, and the sense of fusion is always painfully incomplete.

Such comparisons with choreia do not necessarily suggest that the configuration of the monument mimics the effects of a choral performance that took place at a prior funeral. Instead, I offer them in order to show how the monument's very materiality is able to align the social value of carved and inscribed stone with that of other poetic practices. The aesthetic effects of the monument, in this sense, are like those of a choral performance not because one records or imitates the other, but because both are shaped according to a shared basic structure-a structure rooted in genre as a stable feature of the poem, whether it is experienced as carved or sung. ${ }^{63}$ Yet even if the genre is shared between the different contexts, the monument, as a built material presence, amplifies the structure of elegy on its own terms, giving architectural form to the poetic language of mourning. In so doing, it presents not only Ambracia's citizens - including those of us who read the poem — but the very material fabric of the city as shaped by the structure of elegy.

62 These uses of the verb $\chi \alpha \tau \dot{\varepsilon} \chi \omega$ find close parallels in curse inscriptions of the Classical period, where those writing a curse ask Hermes or Persephone to "hold back" ( $\kappa \alpha \tau \varepsilon \dot{\varepsilon} \chi$ ) the target of their curse (see Eidinow 2007: 147). Although emerging in a very different context, the shared use of the verb is suggestive of the animate potentiality of the material object, whether curse tablet or cenotaph, in generating intersubjective connections between individuals in ways that parallel those achieved in choral performance.

63 See also Sarah Olsen's contribution to this volume, which draws on the concept of genre as a form of embodied cultural knowledge to examine it as a stable feature across different performance contexts. 


\section{Conclusion}

When we examine the poem inscribed on the Ambracian polyandrion in isolation, apart from the medium through which it was experienced, it is easy to understand the relationship between its genre and its content as primarily taxonomic: elegy is the genre of lamentation. In contrast, I hope to have shown that genre only becomes visible - only matters - in the context of an encounter with the inscribed monument as a material object, one that asserts itself as a mourner in the first person. The structure of the elegiac couplet, I have argued, does not communicate lamentation so much as it provides a formalization of mourning that is simultaneously enacted at multiple levels in the configuration of the poem and the monument as a whole.

Understood this way, the choice to inscribe a massive civic cenotaph with a poem in elegiac couplets is significant not because elegy is generically associated with funerary ritual, but because the metrical structure of the couplet-its most basic generic feature-is what enables a community of individuals to experience these deaths on an empathetic level as fellow citizens. It is only as we read the text, as we reorient our movement, as we perceive the tricola that create fissures in the regular pattern of the text, as we mark out the disjunctive structure and content of the couplets on the surface, as we understand that the carefully carved façade we see has no interior, that the dead that we are commanded to know remain forever out of reach-it is only through this process that we come to terms with the monument, and it is only through this encounter that the genre of the poem gains any real meaning. 